\title{
Evaluation of patients' assessment of day hospital care
}

\author{
H. PEACH AND M. S. PATHY \\ From the University Hospital of Wales, Cardiff
}

SUMMARY The method of linear analogue self-assessment (LASA) was used to quantify the views concerning day care which were held by patients attending a geriatric day hospital. The results suggest that day hospitals are an acceptable form of care for the elderly.

Although during the past 18 years there has been a steady increase in the number of geriatric day hospitals in the UK, the attitude of the patients to day hospital care has been largely ignored. The few measurements of the success of day hospitals have been objective-such as, ultimate outcome for the patients (Woodford-Williams et al., 1962; Blake, 1968; Brocklehurst, 1970; Millard and Martin, unpublished). To try to find out the patients' views on day hospital care the technique of LASA was introduced at the St David's Day Hospital, Cardiff.

\section{Patients and methods}

For this study 15 questions were used covering most aspects of day hospital care (Table 1). For each question a $5 \mathrm{~cm}$ or $10 \mathrm{~cm}$ line was drawn and the ends of the line were labelled with words descriptive of the extremes of the response. The patient was asked to mark the line at the point most appropriate to her feelings at that moment. The distance in $\mathrm{cm}$ along the line to this mark (questions 4, 6-8, 10, 12, 14, 15) or from the centre of the line to mark (questions 1-3, 5, 9, 11, 13) gave a score out of 5 . The questions were read to the patients by two lay persons who were not involved in the day hospital but who had extensive experience of interviewing patients. Patients attending the day hospital for the first time were interviewed at the end of the first month after their admission.

To assess the reliability of the technique a sample of patients completed the questionnaire with each of the interviewers separately in the same week, and a further sample completed the questionnaire alone and again with an interviewer in the same week.

\section{Results}

Fifty-one patients were used in the study of whom 19

\section{Table 1 Questionnaire completed by patients}

Dear Patient,

By answering the following questions you will tell us how beneficial your time at the day hospital has been. To answer each question your time at the day hospital has been. To answer each question
simply mark the line with an $X$ at the point most near to your present simply mar

1. Is the time you leave home in the mornings too early

(0) (5) (0)

2. Is the time you get home in the evenings too late too early. (0) (5) (0)

3. Is the amount of time you spend travelling each day too long

(0)

(5) (0)

4. Is the journey to and from the day hospital not enjoyable (0) (5) ery enjoyable.

. Is the amount of time you spend at the day hospital each day too long (0) too short.

6. How helpful has the day hospital been not helpful

(0) (5)

7. How enjoyable is it to attend the day hospital not enjoyable

(0) (5)

very enjoyable.

8. How helpful is the time you spend with the doctor not helpful (0) (5) very helpful.
with the doctor

9. Is the amount of time you spend with the doctor each day too short (0) (5) (0) too long.

10. How helpful is the time you spend with the physiotherapists not helpful

(0) (5) very helpful.

11. Is the amount of time you spend with the physiotherapists too short (0) (5) (0)

12. How helpful is the time you spend with the occupational therapists not helpful (0) (5)

13. Is the amount of time you spend with the occupational therapists too long (0) (5) (0) too short.

14. How helpful is the time when you are not with the doctor or a physical therapist not helpful

(0) very helpful.

15. How keen would you be to attend a day hospital again if the need arose? not keen

(0) very keen. 
were men. The number of patients excluded because they had poor vision or were confused was small. The mean age of the men was 75 years (range 65-83) and that of the women 76 years (range 66-88). Most of the patients were brought to the day hospital by ambulance, only three using private transport. All but eight patients, seven women and one man, received physical treatment. All patients received medical and nursing care and in 14 of the subjects, five men and nine women, there was an element of social care.

Correlation between the patients' scores obtained by the two interviewers in the replicated sample was $\operatorname{good}(r=0 \cdot 85)$. However, correlation between the patients' scores obtained with and without the interviewer present was poor.

The mean score for each of the 15 questions is shown in Table 2. The mean score for most of the questions was high. Both the men and the

Table 2 Mean score for each of the 15 questions by sex of patient

\begin{tabular}{lll}
\hline & \multicolumn{3}{l}{ Mean score } \\
\cline { 2 - 3 } & Men & Women \\
\hline 1 & $4 \cdot 0$ & $4 \cdot 5$ \\
2 & $3 \cdot 8$ & $4 \cdot 1$ \\
3 & $4 \cdot 1$ & $4 \cdot 5$ \\
4 & $3 \cdot 1$ & $4 \cdot 0$ \\
5 & $3 \cdot 5$ & $4 \cdot 1$ \\
6 & $4 \cdot 1$ & $4 \cdot 3$ \\
7 & $3 \cdot 8$ & $4 \cdot 1$ \\
8 & $4 \cdot 4$ & $3 \cdot 3$ \\
9 & $3 \cdot 9$ & $3 \cdot 8$ \\
10 & $4 \cdot 3$ & $4 \cdot 0$ \\
11 & $4 \cdot 1$ & $4 \cdot 4$ \\
12 & $3 \cdot 5$ & $4 \cdot 1$ \\
13 & $3 \cdot 9$ & $4 \cdot 3$ \\
14 & $4 \cdot 3$ & $4 \cdot 1$ \\
15 & $4 \cdot 2$ & $4 \cdot 5$ \\
\hline
\end{tabular}

women were keen to attend a day hospital again if the need arose. However, there was a difference in the mean score for some of the questions between the men and the women. The men did not find the journey to and from the day hospital as enjoyable as did the women. Moreover the men were dissatisfied with the amount of time they spent at the day hospital each day (11 indicated it was too much, only eight indicated that it was about right) and did not find the time spent with the occupationa therapists as helpful as did the women. The women on the other hand did not find the time spent with the doctor as helpful as did the men.

\section{Discussion}

Correlation between the patients' scores with and without the interviewers was poor as many of the patients who appeared to understand the instructions on the questionnaire failed to follow them when answering the questions by themselves. With the interviewers the LASA technique proved an easily ? quantifiable way for the patients to record their $\overrightarrow{\vec{J}}$ assessments of day hospital care. The good ${ }^{\omega}$ correlation between the scores obtained by the $\Phi$ two interviewers proved it to be reliable.

The high scores given by the patients suggest that on the whole they found the day hospital $\omega$ a satisfactory form of care. Women more than men $N$ tend to have multiple conditions and this may be one reason why they found the medical care less beneficial. Fifty-three per cent of the women had $\vec{c}$ three or more serious conditions compared wi 1 ( $\mathbb{D}$ only $26 \%$ of the men. Much of the occupation 1 therapy at St David's Day Hospital includes usefût 3 activities of greater appeal to women and the results were not unexpected.

We thank Mrs Jean Watson and Miss Shen Watson for interviewing the patients and Miss A. R. McKelvie for typing the manuscript.

Reprints from H. Peach, 51 Arles Road, Cardiff CF5 5AN.

\section{References}

Blake, D. H. (1968). A day hospital for geriatric patients: The first twelve months. Medical Journal of Australia, 2, 802-804.

Brocklehurst, J. C. (1970). The Geriatric Day Hospital.? King Edward's Hospital Fund for London: London.

Woodford-Williams, E., McKeon, J. A., Trotter, I. S., Watson, D., and Bushby, C. (1962). The day hospitalo in the community care of the elderly. Gerontology Clinics, 4, 241-256. 